\section{The set size effect and confidence in reports of behavioral intentions}

\author{
EMIL J. POSAVAC* and JACK McKILLIP \\ Loyola University of Chicago, Chicago, Ill. 60626
}

The generality of the principles of impression formation was explored using marital and employment behavioral intentions in a design controlling four levels of description polarity and three levels of set size. In addition, several hypotheses were tested relating confidence in the behavioral intention rating to polarity and amount of information presented. In general, the findings paralleled those obtained when standard evaluative judgments are requested. The reports of confidence increased as polarity and amount of information increased. Some differences in marital and employment behavioral intentions were noted.

There has been widespread evidence for the polarization of impressions as homogeneous information about a stimulus person is increased (Anderson, 1967; Brewer, 1968; Posavac \& Pasko, 1971). This phenomenon has been called the "set size effect" by Anderson (1967). While the effect is very reliable, the processes lying behind it have not been explored. Brewer (1968) reasoned that as homogeneous information increases, people become more confident that the stimulus satisfies or does not satisfy the implicit criteria the judge (or $\mathbf{S}$ ) has developed. If this is so, then the confidence that a $S$ expresses concerning his impressions should increase as the amount of information increases.

Another approach to the way people respond to information is suggested by Jones \& Davis (1965). They maintain that as behavior or personal attributes depart from the norm, judges have more information about the individual being observed. While Jones and Davis emphasize undesirable social behavior, presumably both very good and very bad information supplied by a third person could provide a judge with more information compared to a neutral description. Hamilton \& Huffman (1971), however, have shown that negative information is weighted more heavily than positive information when making evaluative and potency judgments. They did not measure confidence in the Ss' judgments.

Another issue of interest in this paper was the generality of the principles of impression formation. Rosenberg \& Olshan (1970) argue for broadening the study of impression formation principles instead of focusing solely on evaluative judgments. Hamilton \& Huffman (1971) utilized judgments of potency

* Reprints may be obtained from the first author at the Department of Psychology, 6525 North Sheridan Road, Chicago, Illinois 60626 . adjectives using 7 -point scales. Half of the judges made marital ratings first and employment second, while the other half made the ratings in the reverse order. Within the marital and employment ratings, the pages containing the traits were randomly ordered. 2 Since the ratings of the male and the female judges correlated .98 for marital desirability and .98 for employment desirability, sex differences of the judges were ignored. Ratings of marital behavioral intentions (MBI) and employment behavioral intentions (EBI) correlated with evaluation ratings (Hamilton \& Huffman, 1971) .96 and .95, respectively, and intercorrelated .98 .

Four subranges of scale values were derived from each of the two sets of scale values. In a manner similar to that originally used by Anderson (1967), the four subranges were called high $(\mathrm{H})$, moderately positive $(\mathrm{M}+)$, moderately negative (M-), and low (L). Each subrange included 10 traits and was separated from the others by approximately 15 traits. Several traits which would have been qualified for inclusion in the subranges on the basis of their scale values were not used because of relatively high scale value standard deviations. In spite of the very high correlation between the marry and employ scale values, the traits which were perceived as the most and least desirable were not identical across the two BI scalings. For example, "interesting," "loving," "nice," and "warm" were in the most desirable marry sublist but not on the most desirable employ sublist. On the other hand, "helpful," "dedicated," "hard-working," and "responsible" were perceived as very desirable in an employee but not in a spouse.

On the basis of the sets of traits chosen, 21 types of trait combinations were constructed. For each of the four subranges or polarities, there were stimuli defined by one, two, and four traits. Nine other stimulus combinations which were formed to examine questions not discussed here can be considered filler stimuli. Each one of the filler stimuli was made up of traits selected from two subranges. Two forms of each combination were prepared for both BI dimensions. The combinations were arranged in six different orders. Thus, there were a total of 12 different questionnaires for marital and 12 for employment $\mathrm{BIs}$.

\section{PROCEDURE}

The Ss responded to either the marital or the employment questionnaire. The Ss were requested to read a stimulus combination and to think of what a person would be like who possessed those traits (opposite sex for the marital condition and same sex for the employment condition). 
Table 1

Mean Behavioral Intention Ratings of the Trait Combinations

\begin{tabular}{|c|c|c|c|c|c|}
\hline \multirow{2}{*}{$\begin{array}{l}\text { Behavioral } \\
\text { Intention } \\
\text { Dimension }\end{array}$} & \multirow[b]{2}{*}{ Subrange } & \multicolumn{3}{|c|}{ Set Size } & \multirow{2}{*}{$\begin{array}{l}\text { Sub- } \\
\text { range } \\
\text { Means }\end{array}$} \\
\hline & & 1 & 2 & 4 & \\
\hline \multirow{4}{*}{ Marry } & L & 5.23 & 2.83 & 1.73 & 3.27 \\
\hline & $\mathrm{M}-$ & 10.38 & 6.87 & 4.18 & 7.14 \\
\hline & $\mathrm{M}+$ & 12.30 & 13.60 & 15.22 & 13.71 \\
\hline & $\mathrm{H}$ & 12.82 & 16.92 & 17.75 & 15.83 \\
\hline \multicolumn{2}{|c|}{ Set-Size Means } & 10.18 & 10.05 & 9.72 & \\
\hline \multirow{4}{*}{ Employ } & $\mathrm{L}$ & 6.71 & 2.78 & 1.98 & 3.82 \\
\hline & $\mathrm{M}-$ & 9.11 & 10.60 & 6.03 & 8.58 \\
\hline & $\mathrm{M+}$ & 11.22 & 11.28 & 14.57 & 12.36 \\
\hline & $\mathrm{H}$ & 15.15 & 15.47 & 17.36 & 15.99 \\
\hline \multicolumn{2}{|c|}{ Set-Size Means } & 10.55 & 10.03 & 9.97 & \\
\hline
\end{tabular}

Table 2

Mean Estimates of Confidence in the Ratings of the Trait Combinations

\begin{tabular}{|c|c|c|c|c|c|}
\hline \multirow{2}{*}{$\begin{array}{l}\text { Behavioral } \\
\text { Intention } \\
\text { Dimension }\end{array}$} & \multirow[b]{2}{*}{ Subrange } & \multicolumn{3}{|c|}{ Set Size } & \multirow{2}{*}{$\begin{array}{l}\text { Sub- } \\
\text { range } \\
\text { Means }\end{array}$} \\
\hline & & 1 & 2 & 4 & \\
\hline Marry & $\begin{array}{l}\mathrm{L} \\
\mathrm{M}- \\
\mathrm{M}+ \\
\mathrm{H}\end{array}$ & $\begin{array}{l}6.68 \\
5.55 \\
5.33 \\
5.98\end{array}$ & $\begin{array}{l}7.27 \\
6.10 \\
5.93 \\
7.28\end{array}$ & $\begin{array}{l}8.07 \\
7.12 \\
6.75 \\
7.73\end{array}$ & $\begin{array}{l}7.34 \\
6.26 \\
6.00 \\
7.00\end{array}$ \\
\hline \multicolumn{2}{|c|}{ Set-Size Means } & 5.89 & 6.64 & 7.42 & \\
\hline Employ & $\begin{array}{l}\mathrm{L} \\
\mathrm{M}- \\
\mathrm{M}+ \\
\mathrm{H}\end{array}$ & $\begin{array}{l}5.94 \\
5.84 \\
5.55 \\
6.68\end{array}$ & $\begin{array}{l}7.23 \\
5.86 \\
5.76 \\
7.05\end{array}$ & $\begin{array}{l}7.46 \\
5.87 \\
6.58 \\
7.74\end{array}$ & $\begin{array}{l}6.88 \\
5.86 \\
5.96 \\
7.16\end{array}$ \\
\hline \multicolumn{2}{|c|}{ Set-Size Means } & 6.03 & 6.47 & 6.91 & \\
\hline
\end{tabular}

Then they were to report on a 21-point scale how likely it was, given the opportunity, that they would marry such a person or that they would employ and effectively direct such a person. Immediately below each BI scale was a 9-point scale on which the Ss indicated their confidence in their BI report. The poles were labeled "not at all sure" to "very sure" that they would behave as reported on the BI scale. Each S worked through the questionnaire at his or her own speed.

\section{SUBJECTS}

The Ss were drawn from the introductory psychology $S$ pool and were completing a course requirement by participating. Sixty Ss responded to the marital acceptance questionnaire and 126 to the employment questionnaire. (This imbalance resulted from an error in a stimulus combination which required further data collection of employment BIs. Since the error did not occur in the stimulus combinations used in this study, the data for all the Ss are reported.)

\section{RESULTS AND DISCUSSION} Set Size Effect

The first hypothesis concerned the generality of the set size effect. Table 1 contains the treatment means for the BI reports. The main effects of polarity in the 4 by 3 by Ss analyses of variance were, of course, highly significant for MBI and EBI. The interactions indicating the increasing polarization of ratings as set size increased were also highly significant for $\mathrm{MBI}$ and $\mathrm{EBI}(\mathrm{F}=39.44$, $\mathrm{df}=$ $6,354, \mathrm{p}<.001$, and $\mathrm{F}=71.49$, $\mathrm{df}=$ $6,750, \mathrm{p}<.001$, respectively). The data closely followed the pattern previously found for evaluative judgments and support the applicability of impression formation principles to reports of BIs.

Confidence in Reported BI

The confidence reports were analyzed using 4 by 3 by Ss analyses of variance. The confidence treatment means for MBI and EBI are presented in Table 2. It was expected that increasing the set size would lead to increased confidence in BIs. This expectation was confirmed for both judgments $(F=48.59, \mathrm{df}=2,118$, $\mathrm{p}<.001$, and $F=35.34, \mathrm{df}=2,250$, $\mathrm{p}<.001$, for $\mathrm{MBI}$ and EBI, respectively). As amount of information increased, confidence increased, as Brewer (1968) implied.

It was also expected that as information became more polarized, confidence in judgments based on that information would increase. The main effects of polarity for MBI and EBI were both highly significant $(F=$ $21.06, \mathrm{df}=3,177, \mathrm{p}<.001$, and $\mathrm{F}=$ $44.17, \mathrm{df}=3,375, \mathrm{p}<.001$ respectively). An examination of Table 2 shows that for equal set sizes confidence was higher for $\mathrm{H}$ and $\mathrm{L}$ stimuli and lower for $\mathrm{M}+$ and $\mathrm{M}-$ stimuli. It took relatively more moderately polarized information to produce the same subjective confidence that was obtained from very desirable or undesirable information. The third hypothesis was thus supported. As information about a person becomes more highly polarized, judgments of $\mathrm{BIs}$ are made more confidently. The last hypothesis suggested that negative information would be more confidently judged than positive information. Directional related measures $t$ tests indicated that for MBI judgments, confidence was greater for one $\mathrm{L}$ trait compared to one $\mathrm{H}$ trait $(\mathrm{t}=2.23, \mathrm{df}=59, \mathrm{p}<.05)$ and four $L$ traits compared to four $H$ traits $(\mathrm{t}=1.23$, df $=59, \mathrm{p}<.15)$. Table 2 indicates that for EBI reports, the reverse of the hypothesis was found. Nondirectional related measures $t$ tests indicated that one $L$ trait yielded less confident judgments than did one $\mathrm{H}$ trait $(\mathrm{t}=3.14$, df $=$ $125, \mathrm{p}<.01$ ) and that four $\mathrm{M}-$ traits led to less confident judgments than did four $\mathrm{M}+$ traits $(\mathrm{t}=3.09, \mathrm{df}=125$, $\mathrm{p}<.01)$. The weak support for Hypothesis 4 for MBI and the two significant reversals for EBI suggests that possessing an undesirable trait leads to greater rejection for potential spouses than for potential employees. Such a situation most likely reflects the different degrees of intimacy and permanency required by the two relationships. A mistake in marriage is more costly than it is in hiring since it is less easy to discipline or to replace an undesirable spouse than an undesirable employee.

\section{GENERAL DISCUSSION}

The demonstration of the set size effect in judgments of MBI and EBI is not surprising, given the high correlation between the marry and employ scale values and those for evaluation. The pattern of the confidence judgments, however, was more interesting. In general, the judgments of confidence increased as information increased and thus support the suggestions made by Brewer (1968) concerning the subjective processes lying behind the set size effect in impression formation. The most interesting aspects of the pattern of the confidence reports was the relation of polarity of the description to confidence in the BI. Confidence was significantly higher when information was either very desirable or very undesirable. Singh (1972) has shown that Ss are more confident of their impressions when adjectival descriptions are uniformly positive or uniformly negative compared to when descriptions were partially positive and partially negative. Since the present $\mathrm{M}-$ and $\mathrm{M}+$ descriptions are analogous to Singh's descriptions which contained both positive and negative information, the present findings complement Singh's.

\section{REFERENCES}

ANDERSON, N. H. Averaging model analysis of set-size effect in impression formation. Journal of Experimental Psychology, 1967, 75, 158-165.

BREWER, M. B. Averaging versus summation in composite ratings of complex social stimuli. Journal of Personality \& Social Psychology, 1968, 8, 20-26.

HAMILTON, D. L., \& HUFFMAN, L. J Generality of impression formation processes for evaluative and 
non-evaluative judgments. Journal of Personality \& Social Psychology, 1971, 20, 200-207.

JONES, E. E., \& DAVIS, K. E. From acts to dispositions: The attribution process in person perception. In L. Berk owitz (Ed.), Advances in experimental social psychology. Vol. 2. New York: Academic Press, 1965.

POSAVAC, E. J., \& PASKO, S. J. Interpersonal attraction and confidence of attraction ratings as a function of number of attitudes and attitude similarity. Psychonomic Science, 1971, $23,433-435$.

ROSENBERG, S \& OLSHAN, K Evaluative and descriptive aspects of personality perception. Journal of Personality \& Social Psychology, 1970, $16,619-626$.

SINGH, R. Evaluative response and certainty of its accuracy as a function of proportion of positive descriptions. Paper presented at the meeting of the Midwestern Psychological Association, Cleveland, May 1972.
TRIANDIS, H. C. Exploratory factor analyses of the behavioral component of social attitudes. Journal of Abnormal \& Social Psychology, 1964, 68, 420-430.

\section{NOTES}

1. The authors thank David L. Hamilton for making these materials available.

2 . The scale values were found by Roger Semyck and Casimir Lorenc and are available from the first author. 